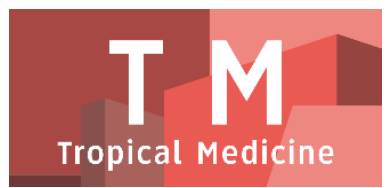

PAPER - OPEN ACCESS

\title{
Penatalaksanaan Fissure Sealent Pada Gigi Anak (Laporan Kasus)
}

\author{
Author : Zulfi Amalia Bachtiar \\ DOI $\quad: 10.32734 /$ tm.v1i1.72 \\ Paper Page : $207-213$
}

Volume 1 Issue 1 - 2018 TALENTA Conference Series: Tropical Medicine (TM)

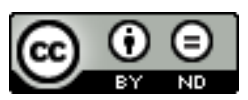

This work is licensed under a Creative Commons Attribution-NoDerivatives 4.0 International License.

Published under licence by TALENTA Publisher, Universitas Sumatera Utara
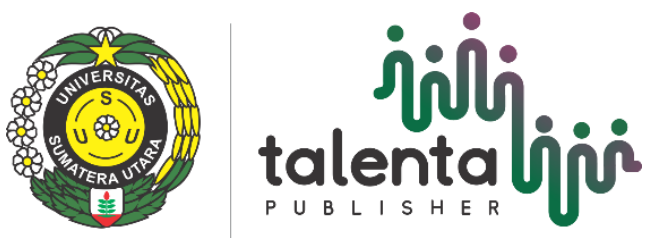


\title{
Penatalaksanaan Fissure Sealent Pada Gigi Anak (Laporan Kasus)
}

\author{
Zulfi Amalia Bachtiara,*, Rizki Amalia Putri ${ }^{\mathrm{a}}$ \\ ${ }^{a}$ Fakultas Kedokteran Gigi, Universitas Sumatera Utara, Medan 20155, Indonesia \\ zulfi.amalia@gmail.com
}

\begin{abstract}
Abstrak
Permukaan oklusal dengan pit dan fisur telah dikenal sebagai daerah yang rentan akan karies, karena anatomi yang spesifik dan ketidakmampuan untuk mengeliminasi plak secara adekuat. Fissure sealant adalah suatu tindakan pencegahan karies pada gigi yang secara anatomis mempunyai pit dan fisur yang dalam yang karenanya lebih gampang terserang karies. Tujuan utama diberikannya sealant adalah agar terjadinya penetrasi bahan ke dalam pit dan fisur serta berpolimerisai dan menutup daerah tersebut dari bakteri dan debris. Kasus ini merupakan tindakan penatalaksanann fissure sealent sebagai upaya pencegahan karies pada gigi anak, teknik ini terbukti efektif mengurangi insiden karies pada pit dan fisur yang merupakan bagian yang rentan karies Pit dan fisur sering terjadi pada gigi geraham, yang memiliki peranan sangat penting yaitu untuk melakukan pengunyahan di permukaannya yang lebar untuk menghaluskan partikel makanan yang sudah kita potong dengan gigi depan, dengan diberikannya bahan penutup pit dan fisur sejak awal erupsi gigi, diharapkan dapat mencegah bakteri sisa makanan berada dalam pit dan fisur.
\end{abstract}

Kata Kunci: Pit Fisur Dalam, Fissure Sealent, Penatalaksanaan

\section{Latar Belakang}

Ilmu kedokteran gigi anak, adalah salah satu yang mempelajari suatu metode pencegahan terhadap terjadinya karies pada gigi anak. Berbagai tindakan pencegahan terjadinya karies telah diupayakan melalui fluoridasi air minum, topikal aplikasi fluor pada fase perkembangan enamel, dan program kontrol plak bagi masing-masing individu. Hal ini tidak terbukti efektif mengurangi insiden karies pada pit dan fisura yang merupakan bagian yang rentan karies, karena bentukan anatomisnya yang menyempit. [1][11]

Karies dental merupakan penyakit kronis yang paling umum pada anak-anak, walaupun faktanya hal ini dapat dicegah. Permukaan oklusal dengan pit dan fisur telah dikenal sebagai daerah yang rentan karies awal karena anatomi yang spesifik dan ketidakmampuan untuk mengeliminasi plak secara adekuat. Keperluan untuk menurunkan prevalansi karies pada gigi anak di negara industri di seluruh dunia, dan karena fluoridasi sistemik dan topikal berefek paling sedikit pada pencegahan karies permukaan pit dan fisur, keperluan pit dan fissure sealant yang efektif menjadi sangat penting. [3]

Penganalisisan dari distribusi karies pada anak di Amerika Utara tahun 1970 menunjukkan bahwa hanya 12,5\% dari total permukaan oklusal gigi permanen yang mengalami karies, yang mengenai $50 \%$ anak usia sekolah. Sejalan dengan penurunan karies dental baru-baru ini, distribusi relatif dari karies di permukaan yang berbeda menjadi berubah, sehingga persentase karies pit dan fisur meningkat. Hal ini telah didemonstrasikan dengan jelas oleh sebuah perbandingan dari distribusi karies pada dua penelitian distribusi karies nasional tahun 1971-1974 dan 1979-1980 di Amerika Utara. Walaupun karies proksimal telah menurun 52,9\%, karies buko-lingual menurun hanya 
26,3\%, sementara karies oklusal menurun 25,7\%. Pit bukal dari molar mandibula dan groove lingual dari molar maksila merupakan daerah yang paling rentan karies oklusal. [11]

Pada survei The National Center for Health Statistics (NCHS) tahun 1974, karies oklusal merepresentasikan 49\% dari total karies. Peningkatan proporsi dari insiden karies pada pit dan fisur adalah akibat dari penurunan prevalansi dari karies permukaan interproksimal. Di antara survey tahun 1974-1991, terjadi pengurangan 78\% karies interproksimal. Survey secara luas (The National Preventive Dentistry Demonstration Program) yang dilakukan oleh American Fund for Dental Health (AFDH) menggunakan sampel kurang lebih 25.000 anak sekolah yang berusia 613 tahun di 5 kota dengan fluoridasi optimal dan 5 kota dengan defisiensi fluoridasi. Karies oklusal ditemukan sebanyak 54\% di kedua kota. Selain itu, distribusi karies pada anak sekolah yang berpartisipasi dalam program kumur-kumur juga mengkonfirmasi tingginya karies pit dan fisur. Setelah 6 tahun pelaksanaan program kumurkumur dengan fluoride, dilaporkan bahwa 94\% dari DMFS melibatkan pit dan fisur, dan hanya $6 \%$ melibatkan permukaan proksimal. [10]

Penelitian menunjukkan bahwa 37\% anak sekolah di Amerika Serikat berusia antara 5-17 bebas karies, hanya 17,2\% dari anak sekolah berusia antara 12-17 tahun bebas karies, dan 89\% dari anak berusia 17 tahun memiliki setidaknya satu lesi karies. Hampir semua lesi karies yang baru pada remaja adalah karies pit dan fisur. [11]

Selain itu, menurut penelitian Weintraub di Australia, ditemukan bahwa oklusal karies merupakan 80-90\% dari semua karies pada anak. Gigi yang memiliki resiko tinggi karies adalah gigi molar pertama dan kedua permanen. Pengaplikasian sealant pada anak-anak yang memiliki resiko tinggi karies adalah efektif, sehingga dapat disimpulkan perluasan pemakaian pit dan fissure sealant harus menjadi prioritas dan kombinasi pemakaian sealant dan kumur-kumur fluoride dapat mencegah karies dental pada gigi permanen anak sekolah. [4][10]

Tujuan dari laporan kasus pada makalah ini adalah untuk mengetahui bagaimana penatalaksanaan fisur sealant pada gigi anak sebagai upaya pencegahan karies.

\section{Fissure Sealant}

\subsection{Definisi, Indikasi dan Kontraindikasi Pit dan Fissure Sealant}

Pit dan fissure sealant adalah suatu tindakan pencegahan karies pada gigi yang secara anatomis mempunyai pit dan fisur yang dalam sehingga lebih mudah terserang karies. Pit dan fisur dibentuk kembali dan diisi dengan bahan sealant agar gigi tersebut menjadi lebih tahan terhadap serangan karies gigi. Hal ini sering ditemui pada gigi geraham yang mempunyai peranan sangat penting untuk melakukan pengunyahan. Permukaannya yang lebar untuk menghaluskan partikel makanan yang sudah dipotong dengan gigi depan. Gigi geraham mempunyai peranan dan bentuk istimewa yang merupakan kelebihannya, tetapi ada kendala yang harus diatasi dengan bijaksana agar fungsi dan keberadaannya dapat terjaga dengan baik. Posisi gigi geraham dalam rongga mulut yang sulit terjangkau juga menyulitkan pembersihan dengan sikat gigi. Beberapa karakteristik gigi geraham yang perlu dipahami antara lain; permukaan kunyahnya luas dan tidak rata, terdapat pit (titik) dan fisur (garis) yang dalam sehingga sulit terjangkau dan menjadi tempat persembunyian kuman yang nyaman. Pit adalah bagian dari permukaan gigi yang berupa titik terdalam yang berada pada pertemuan antar beberapa groove atau akhir dari groove. Istilah pit sering berkaitan dengan fisur. Fisur adalah garis berupa celah yang dalam pada permukaan gigi [7][8]

Morfologi permukaan oklusal gigi bervariasi pada tiap individu. Macam pit dan fisur bervariasi bentuk dan kedalamannya, dapat berupa tipe U (terbuka cukup lebar); tipe V (terbuka, namun sempit); tipe I (bentuk seperti leher botol). Bentuk pit dan fisur bentuk U cenderung dangkal, lebar sehingga mudahdibersihkan dan lebih tahan karies. Sedangkan bentuk pit dan fisur bentuk V atau I cenderung dalam, sempit dan berkelok sehingga lebih rentan karies. Bentukan ini mengakibatkan penumpukan plak, mikroorganisme dan debris. [7][8]. 


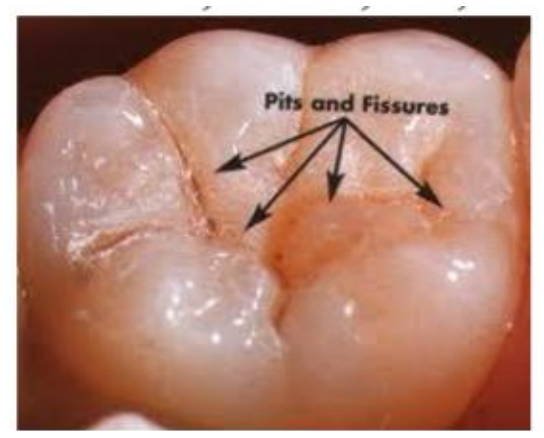

Fig. 1. Pit and Fissures Sealant

Indikasi pemberian sealant pada pit dan fisur adalah sebagai berikut:

- Pit dan fisur dalam

- Pit dan fisur dengan dekalsifikasi minimal

- Tidak adanya karies interproximal

- Memungkinkan isolasi adekuat terhadap kontaminasi saliva

- Umur gigi erupsi kurang dari 4 tahun. [11][13]

Kontraindikasi pemberian sealant pada pit dan fisur adalah sebagai berikut:

- Self cleansing yang baik pada pit dan fisur

- Terdapat tanda klinis maupun radiografis adanya karies interproximal yang memerlukan perawatan dan restorasi

- Gigi erupsi hanya sebagian dan tidak memungkinkan isolasi dari kontaminasi saliva. [11][13]

\subsection{Teori Mengenai Teknik dan Aplikasi Fissure Sealant}

Fissure sealant dapat dibedakan berdasarkan:

- Bahan
a. Resin
b. Ionomer kaca

- Polimerisasi

\section{a. Self-cure}

Sealant ini terdiri dari 2 bahan yang nantinya pada saat dicampurkan sealant akan terpolimerasi lalu mengeras. Keuntungan sealant tipe ini yaitu tidak adanya alat khusus yang dibutuhkan. Kerugiannya adalah waktu yang terbatas karena polimerisasi akan dimulai sejak bahan dicampurkan.

\section{b. Light-cure}

Sealant jenis ini akan mengeras ketika disinar dengan alat curing. Keuntungannya adalah tidak perlu dilakukan pencampuran bahan sehingga akan meningkatkan waktu kerja. Kerugiannya adalah biaya alat curing yang cukup mahal.

\section{- Filler}

\section{a. Filled sealant}

Sealant dapat berisi filler maupun tidak. Sealant yang mengandung filler terdapat partikelpartikel yang terbuat dari kaca atau quartz untuk meningkatkan resistensinya pada saat penggunaan, termasuk tekanan pengunyahan. Namun, sealant ini lebih kental sehingga akan mempengaruhi daya alirnya

b. Unfilled sealant

Sealant yang tidak berisi filler memiliki resistensi yang kurang pada penggunaanya. Sealant ini memiliki viskositas yang rendah sehingga bahan sealant dapat mengalir masuk lebih dalam lagi. Keuntungan lainnya yaitu tidak diperlukan penyelarasan oklusal sehingga bermanfaat jika waktu yang tersedia sedikit seperti pada saat diadakannya program kesehatan sekolah [5]. 


\section{Laporan Kasus Dan Penatalakasanaan Fissure Sealant}

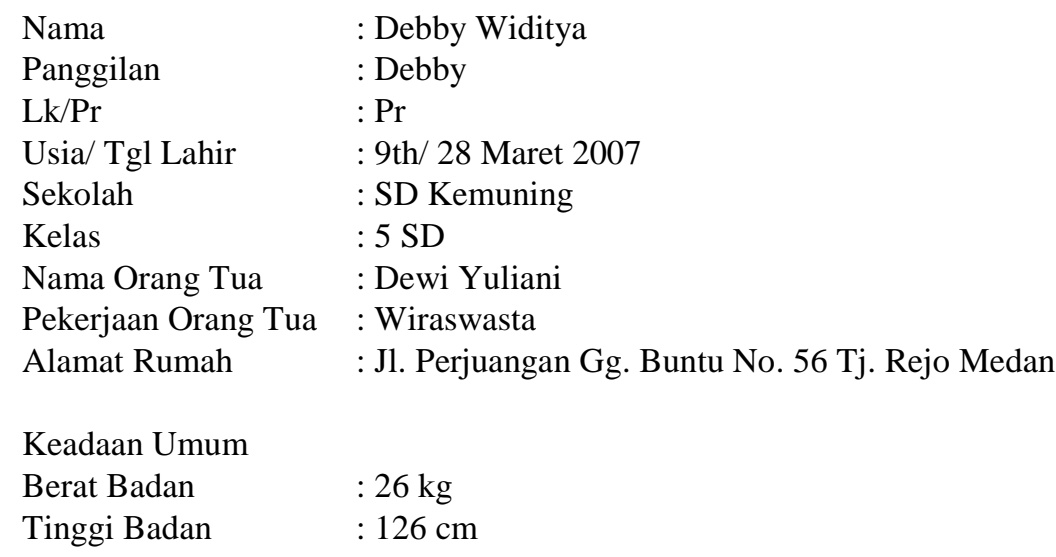

Keluhan Utama

Pasien datang ingin memeriksakan gigi geraham atas kiri. Setelah dilakukan pemeriksaan didapati adanya pit dan fissure yang dalam pada gigi 26.

Pemeriksaan Sekitar Mulut

Bentuk Muka : Simetris

Pembengkakan : TAA

Kelenjar Getah Bening : TAA

Kelenjar Parotis $\quad$ : TAA

Pemeriksaan Rongga Mulut

Jaringan Lunak Mulut Bibir : Normal

Perlekatan Frenulum : Normal

Mukosa Labial : Normal

Mukosa Bukal : Normal

Gingiva : : Normal

Palatum : Normal

Lidah : Normal

Tonsil : Normal

Skor Plak

\begin{tabular}{|l|l|l|}
\hline 1 & 2 & 1 \\
\hline $6 / \mathrm{E}$ & $1 / \mathrm{A}$ & $6 / \mathrm{E}$ \\
\hline 1 & 2 & 1 \\
\hline
\end{tabular}

1,3 : Sedang

Gigi yang Ada

\begin{tabular}{|c|c|c|c|c|c|c|c|c|c|c|c|c|c|c|c|}
\hline \multicolumn{8}{|c|}{ Pit dan Fisser Dalam } & \multicolumn{8}{|c|}{ Pit dan Fisser Dalam } \\
\hline 8 & 7 & 6 & 5 & 4 & 3 & 2 & 1 & 1 & 2 & 3 & 4 & 5 & 6 & 7 & 8 \\
\hline 8 & 7 & 6 & 5 & 4 & 3 & 2 & 1 & 1 & 2 & 3 & 4 & 5 & 6 & 7 & 8 \\
\hline
\end{tabular}




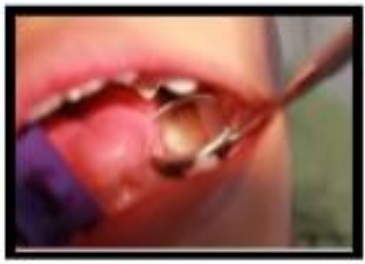

Fig. 2. Pit dan fisur yang dalam pada gigi 26 yang mengindikasikan perawatan fissure sealant

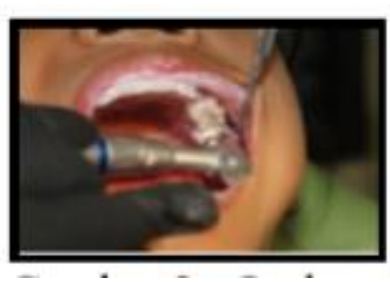

Fig. 3. Oral profilaksis yang bertujuan menghilangkan debris makanan

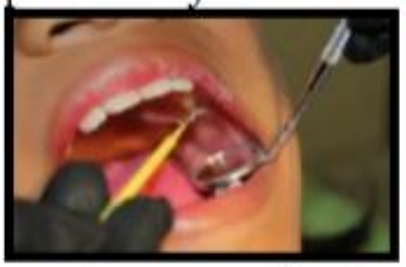

Fig. 4. Aplikasi etsa selama $30-$ 60 detik dengan bahan asam fosfat $37 \%$ pada gigi 26 .

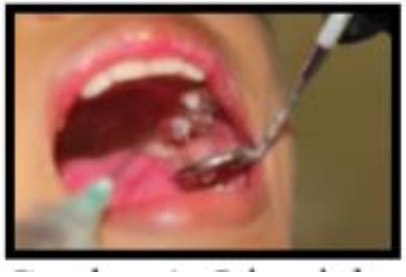

Fig. 5. Irigasi dengan Air selama 10 detik

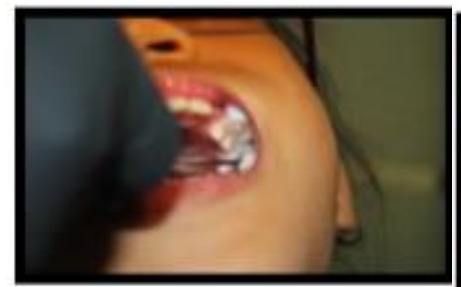

Fig. 6. Pengeringan selama 10 detik (terlihat permukaan yang berwarna keputihan) dan isolasi daerah kerja

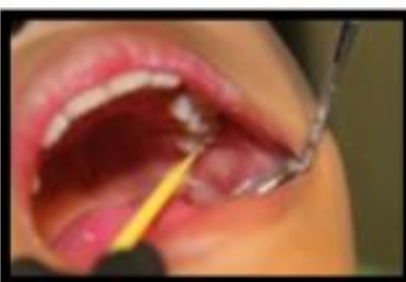

Fig. 7. Aplikasi Bonding

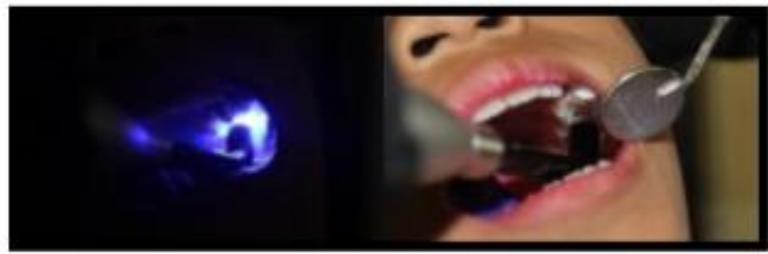

Fig. 8. Penyinaran dengan menggunakan light cure selama 20 detik pada gigi 26

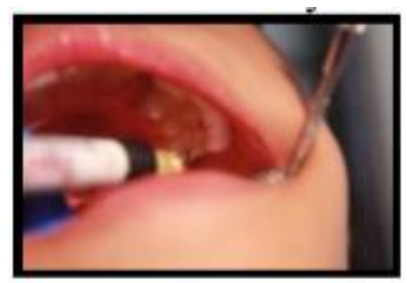

Fig. 9. Aplikasi sealant pada gigi 26 , dimulai dari tonjol yang paling tinggi dan menutup seluruh Pit dan Fisur yang dalam

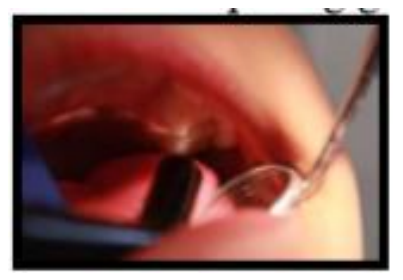

Fig. 10. Setelah aplikasi Sealant, lalu lakukan penyinaran dengan light cure pada gigi 26 selama 2030 detik

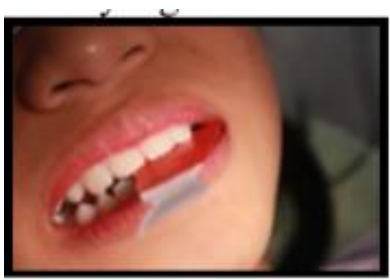

Fig. 11. Kemudian pengecekan traumatik oklusi dengan menggunakan artikulating paper, untuk melihat traumatik oklusi

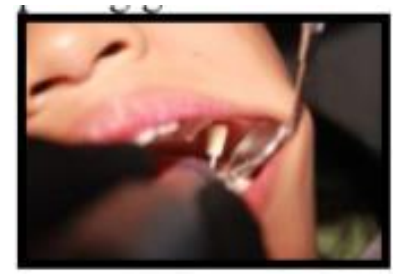

Fig. 12. Polishing pada Gigi 26 yang bertujuan untuk menghaluskan permukaan yang kasar

\section{Pembahasan}

Pengaplikasian bahan fisur sealant pada gigi telah terbukti memiliki keefektifan tinggi dalam pencegahan karies yang didasarkan penutupan pit dan fisur sehingga mikroflora dalam pit dan fisur tidak dapat menjangkau nutrisi yang dibutuhkan. Bahan sealant ini akan menutup fisur yang dalam sehingga tidak lagi menjadi tempat perlekatan plak dan sisa makanan dan gigi menjadi lebih mudah dibersihkan.[13] 
Bermacam-macam teknik dan material telah dianjurkan untuk mencegah karies pada area rentan, pit dan fisur gigi posterior, khususnya pada gigi anak. Teknik sealant yang paling popular adalah menggunakan material resin yang diaplikasikan ke permukaan oklusal gigi. Material resin berpenetrasi ke dalam pit dan fisur dari gigi, kemudian berpolimerisasi dan menutup terhadap flora oral dan debris. Secara umum resin memiliki sifat mekanis yang baik sehingga dapat digunakan pada gigi dengan beban kunyah besar, kelarutan bahan resin yang sangat rendah, sifat termis bahan resin sebagai isolator termis yang baik, koefisien termal yang tinggi, dan kebanyakan resin bersifat radioopak sehingga warna lebih estetis. [13]

Keberhasilan dari teknik sealant sangat tergantung pada dicapainya dan terjaganya adaptasi yang erat antara sealant dengan permukaan gigi. Oleh karena itu, sealant harus memiliki viskositas yang relatif rendah sehingga dapat bertahan lebih lama dan kuat karena memiliki kemampuan penetrasi yang lebih bagus. Hal ini karena adanya proses etsa pada enamel gigi yang menghasilkan kontak yang lebih baik antara bahan resin dengan permukaan enamel. Bentukan hasil etsa menghasilkan struktur yang memungkinkan penetrasinya ke dalam enamel dan membentuk ikatan mekanikal yang efektif. Kerugian dari bahan resin adalah retensi pada struktur gigi hanya tergantung pada jumlah perlekatan mekanisnya. [13].

Suatu bahan sealant yang ideal harus mempunyai koefisien ekspansi termal yang sesuai dengan koefisien ekspansi termal dari gigi, memungkinkan sealant berkontraksi atau berekspansi terhadap perubahan suhu menyerupai enamel. Tetapi pada kenyataannya sehari-hari pengaruh suhu dari makanan dan minuman akan menyebabkan perbedaan ekspansi termal dari bahan sealant dan gigi yang kemungkinan akan menyebabkan kebocoran dari tepi sealant. [8]

Mikroleakage (kebocoran tepi) adalah kebocoran mikro antara tepi restorasi dengan permukaan gigi sehingga memungkinkan bakteri, saliva, dan debris masuk kedalam fisur sehingga dapat menyebabkan karies sekunder. Kebocoran tepi terjadi karena adanya perbedaan koefisien ekspansi termal antara bahan sealant dengan gigi, karena terjadinya shrinkage selama polimerisasi atau karena aplikasi bahan sealant tanpa melalui proses bonding. [8].

Sebuah laporan kasus menyatakan bahwa sealant ionomer kaca mengalami kehilangan sebagian besar permukaan tekstur daripada resin sealant. Hal ini sangat signifikan dari evaluasi setelah 6 bulan, yang dapat dihubungkan dengan beban pengunyahan dari sealant ionomer kaca pada beban di oklusal sehingga menyebabkan disentrigasi permukaan dengan cepat. Sealant yang menipis dan akhirnya terjadi fraktur pada permukaan enamel. Kombinasi pada dua faktor ini sepertinya menjadi alasan utama untuk hilangnya sealant ionomer kaca. Perbaikan yang lebih lanjut pada sealant ionomer kaca harus didorong agar menghasilkan pemakaian bahan yang lebih resisten untuk menahan beban pengunyahan. [9].

Namun beberapa penelitian juga menunjukkan sealant ionomer kaca memiliki kemampuan mencegah karies, dengan manipulasi lebih mudah, dan aplikasinya tidak memerlukan proses etsa terlebih dahulu. Sealant ionomer kaca lebih memungkinkan dilakukannya sealant pada kondisi-kondisi sulit. Sulitnya kontrol terhadap kondisi lembab pada gigi yang belum erupsi sempurna, dan sulitnya manajemen pasien anak adalah beberapa kesulitan aplikasi sealant. Aplikasi yang mudah sangat mengurangi waktu tindakan. Bahan yang kompatibel dan mempunyai koefisien termal yang lebih rendah dari struktur gigi. Keuntungan lainnya adalah kemudahan penggunaan dalam program kemasyarakatan karena waktunya cepat dan efektif. [2]

Sekali diterapkan, sealant perlu dipertahankan. Ketika sealant diterapkan pada resiko karies tinggi dari anakanak, peninjauan ulang terhadap retensi sealant harus dilakukan dengan kunjungan berulang. Pedoman awal di tahap ini telah direkomondasikan bahwa kunjungan berulang untuk risiko karies tinggi dari anak-anak harus dilakukan tidak melebihi 12 bulan. Jika isolasi sulit dicapai atau sealant telah diaplikasikan di atas suatu lesi yang mencurigakan, kunjungan berulang harusnya dilakukan dalam waktu 6 bulan. Sebuah studi selama 3 tahun yang melibatkan sampel anak berusia 5-14 tahun dengan sebagian atau gigi molar pertama atau kedua permanen yang baru erupsi ditemukan bahwa tingkat perawatan kembali lebih tinggi kunjungan berulang enam bulan pertama dari pada kunjungan berulang lainnya selama studi itu dilakukan. [2]

\section{Kesimpulan}

- Tujuan utama fissure sealant yaitu agar terjadi penetrasi bahan ke dalam pit dan fisur dan menutup daerah tersebut dari bakteri dan debris. 
- Sealant berbasis resin memiliki kemampuan retensi yang lebih baik daripada ionomer kaca

- Bahan sealant berbasis resin digunakan pada gigi dengan beban kunyah besar, dan mahkota gigi telah erupsi sempurna.

- Bahan sealant ionomer kaca digunakan pada gigi dengan beban kunyah ringan, dengan pengaplikasiannya yang efektif dan cepat sangat diindikasikan untuk pasien anak yang kurang kooperatif.

\section{Referensi}

[1] Bayrak S et all. (2010) Fluoride release and recharge from different materials used as fissure sealants. European J of Dent. 4: $245-50$.

[2] Hiiri A et all. (2012) Pit-and-fissure sealants are ore effective than fluoride varnish in caries prevention on occlusal surfaces. J Evid Base Dent Pract. 12: 74-6.

[3] Kantovitz KR et all. (2013). Inhibition of enamel mineral loss by fissure sealant: an in situ study. J of Dent: 41: 42-50.

[4] Kementerian Kesehatan RI. (2012). Pedoman usaha kesehatan gigi sekolah (UKGS). Jakarta. 30-3.

[5] Liu BY et all. (2014) Glass ionomer ART sealant and fluoride-releasing resin sealant in fissure caries prevention- results from a randominzed clinical trial. BMC Oral Health: 14(54): 1-9.

[6] Lindemeyer RG. (2007) The use of glass ionomer sealants on newly erupting permanent molars. J Canadian Dent A. 73(2): 131-4.

[7] Ministry of Health. (2013) Pit and fissure sealants: use of oral health services NSW. Health Policy Statement. 25: 1-10.

[8] Munos HE et all. (2013) Pit and fissure sealants: an overview. Academy of General Dentistry: 96-8.

[9] Ninawe N et all. (2012). A 1-year clinical evaluation of fissure sealants on permanent first molars. Contemporary Clinical Dent. 3: 54-9.

[10] Pinkham JR et all. (2005). Pediatric dentistry infancy through adolescence fourth edition. China, Elsevier Saunders. 520-31.

[11] Stephen HY et all. (1988) Pediatric dentistry: total patient care. Philadelphia. Lea \& Febiger. 47-56

[12] Sener Y et all. (2014) Polymerization shrinkage of six different fissure sealants. J of Restorative Dent. 2(2): 88-91

[13] Simonsen RJ, Neal RC. (2011) A Review of the clinical application and performace of pit and fissure sealants. Australian Dent J. 56: 45-58 